\title{
Occult capitate fracture through a bone island - SPECT/CT arthrography imaging
}

Klaus Strobel ${ }^{1}$, Lidija Antunovic ${ }^{2^{*}}$ (D) Wouter van der Bruggen ${ }^{3}$, Gopinath Gnanasegaran ${ }^{4}$, Willm Uwe Kampen ${ }^{5}$, Tim Van den Wyngaert ${ }^{6}$, Edmond Rust ${ }^{7}$, Torsten Kuwert ${ }^{8}$ and Frédéric Paycha ${ }^{9}$

\author{
*Correspondence: lidija.antunovic@ \\ humanitas.it \\ ${ }^{2}$ Department of Nuclear Medicine, \\ Humanitas Clinical and Research \\ Hospital, Rozzano, Milan, Italy \\ Full list of author information is \\ available at the end of the article
}

\begin{abstract}
Background: Single photon emission tomography/computed tomography (SPECT/ $\mathrm{CT}$ ) combines the strengths of bone scintigraphy and $\mathrm{CT}$ and serve as an important alternative to magnetic resonance (MR) imaging in carpal trauma patients if conventional $\mathrm{x}$-rays are equivocal.

Case presentation: In a young patient with pain 4 days after carpal trauma conventional x-rays were negative for fracture and MR showed only bone bruise. SPECT/CT arthrography one month later revealed intensive uptake in the capitate bone corresponding to a fracture through a bone island on the $C T$ part of the study.

Conclusion: SPECT/CT combines the sensitivity of bone scintigraphy and specificity of (diagnostic) CT and might serve as an important second line imaging modality for the detection of occult carpal fracture.
\end{abstract}

Keywords: Capitate fracture, SPECT/CT arthrography, Occult fracture

\section{Background}

Fractures of the carpals are very rare and sometimes difficult to detect with conventional $\mathrm{x}$-rays. CT and bone scintigraphy are superior to conventional $\mathrm{x}$-rays in the detection of carpal fractures (Akdemir et al., 2004; Welling et al., 2008). Since SPECT/ $\mathrm{CT}$ is available it has been successfully used for imaging of patients with unclear carpal and wrist pain (Huellner et al., 2012).

\section{Case presentation}

We report a case of a 27-year old male patient with carpal pain 4 days after falling from a ladder. Conventional radiographs were negative for fracture. MR (Fig. 1) showed some bone bruise (A,B short arrows) and a bone island (A,B, long arrow) and the patient was referred for SPECT/CT arthrography. SPECT/CT arthrography (Fig. 2) was performed one month later with the technique described before (Bhure et al., 2017). Planar bone scintigraphy (A) and SPECT (C) images showed intensive focal uptake in the capitate bone (long arrows) corresponding to a transverse fracture on CT (D, short arrow). Incidentally the fracture went through a homogeneously dense lesion with distinctive radiating bony streaks (known as "thorny radiations"), typical for a bone island or enostosis (D, long arrow). Triangular fibrocartilage complex (TFCC), 


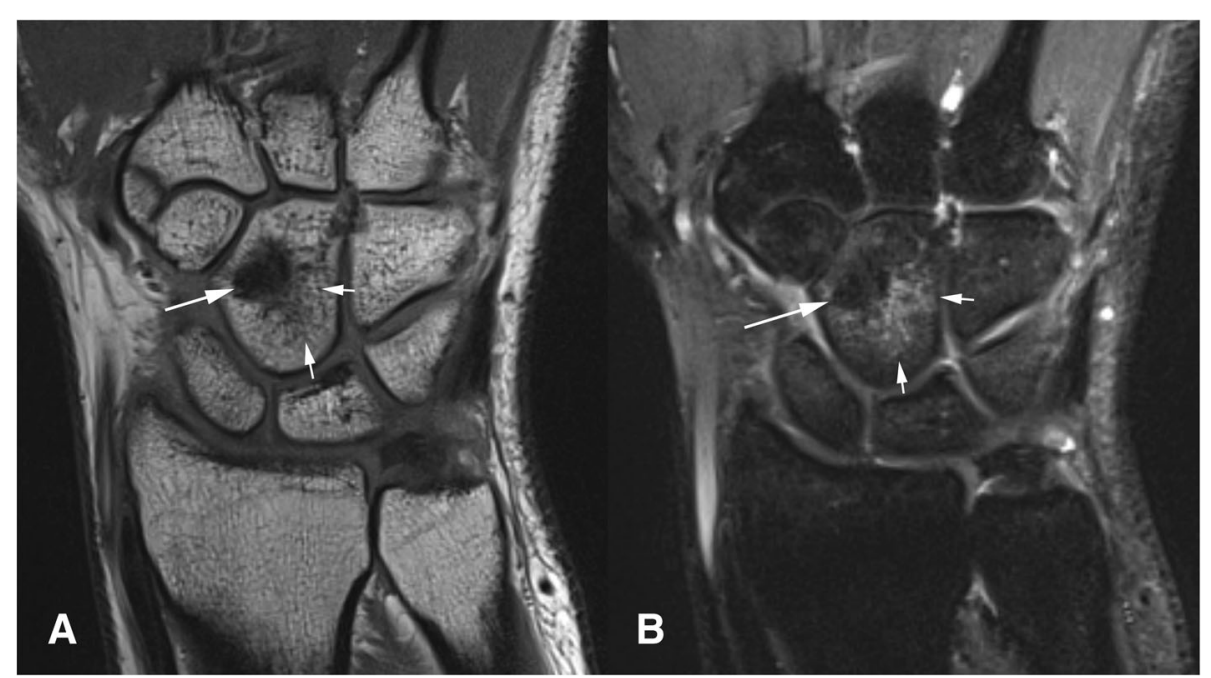

Fig. 1 MR images in a patient 4 days after carpal trauma at the same day with bone bruise (short arrows) in the capitate and a bone island (long arrow). Coronal T1 (a). Coronal STIR (b)

A

\section{c}
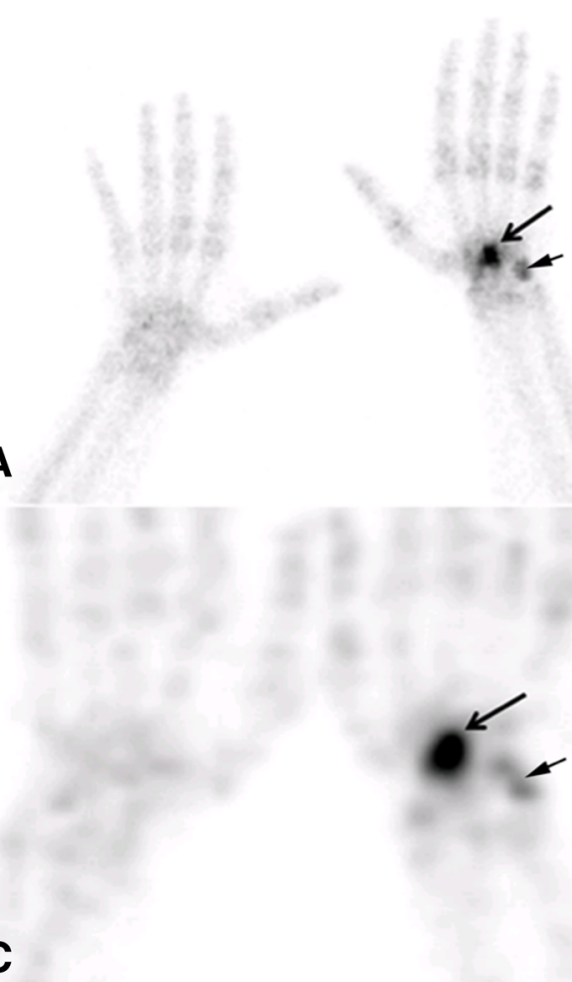

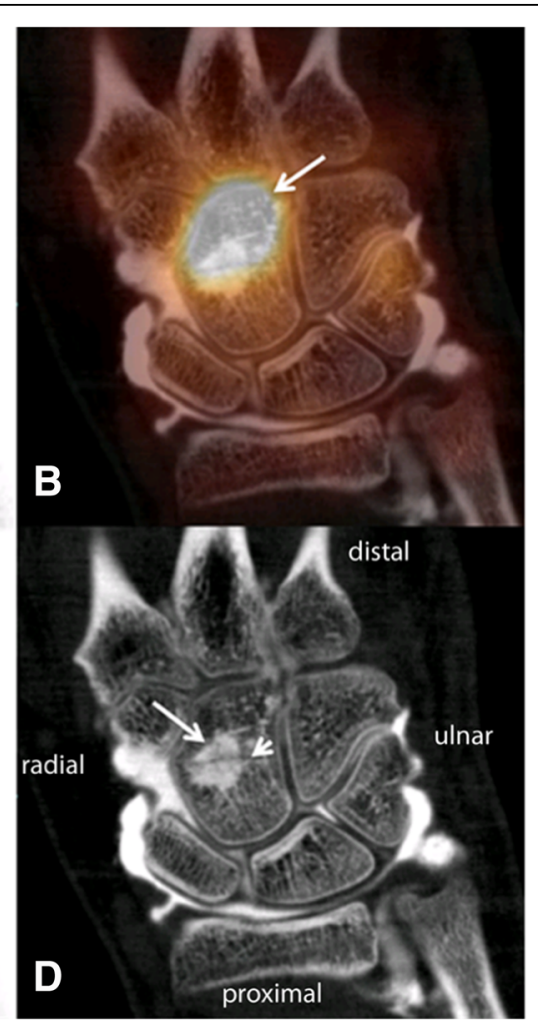

Fig. 2 SPECT/CT arthrography in a patient 1 month after carpal trauma with capitate fracture (short arrow in D) through a bone island (long arrow in D). Planar bone scintigraphy (a) SPECT (c) and SPECT/CT (b) with increased uptake in the capitate (arrow). SPECT/CT arthrography (b). CT arthrography (d) showing intact ligaments and cartilages. Additionally, slightly increased traumatic uptake in the pisiforme bone (short arrow) is visible on planar images and SPECT 
scapholunar (SL) and lunotriquetral (LT) ligaments were intact. The patient was treated with a splint. CT follow-up after 3 months showed successful fracture healing.

\section{Discussion}

Carpal fractures besides scaphoid fractures are very rare (approx. 1\% of all fractures) and often difficult to diagnose with conventional imaging. De Zwart et al. compared SPECT/CT to planar bone scintigraphy in ten patients with carpal trauma and found more accurate anatomic description of fractures with SPECT/CT in three patients (de Zwart et al., 2015). Allainmat et al. confirmed the superiority of SPECT/CT in the detection of posttraumatic bone lesions after carpal injury (Allainmat et al., 2013). The additional use of intraarticular contrast, known as SPECT/CT arthrography, enables the evaluation of important structures like TFCC, LT ligament and SL ligament as well as the cartilage (Bhure et al., 2017). Since wrist and carpal fractures are often associated with ligament tears the combination of SPECT and CT arthrography in one imaging application allows the detection of these therapeutically relevant additional injuries (Klempka et al., 2016; Lee et al., 2013). Because arthrography is a minimally invasive procedure with very low risk of complications, such as infection, it should be applied selectively if ligament or cartilage injuries are clinically suspected. Typical appearance of fractures in MR are hypointense lines surrounded by bone marrow edema (Shepard et al., 2014). Querellou et al. compared SPECT/CT and MR in 52 patients and confirmed the good performance of SPECT/CT in carpal fractures (Querellou et al., 2014). They described in 6 cases fractures in SPECT/CT where corresponding MR showed only bone bruise. A capitate fracture did not occur in their series. In this presented case the fracture coincides incidentally with a bone island. Bone islands (enostosis) are benign congenital or developmental bone alterations representing compact bone within cancellous bone (Greenspan, 1995). They are typically asymptomatic incidental findings on imaging. On CT bone islands appear as alterations denser than cortex and creating a brush-like border. Prevalent anatomical localizations are femurs, hands, humeri, pelvic girdle, and ribs. The majority (75\%) of enostosis display normal uptake on planar bone scintigraphy, even if SPECT and SPECT/CT modalities have disclosed some "warm" enostosis which are inconspicuous on planar scintigraphy (Achong, 2007). Some bone islands are "hot" on bone scan and should not be misdiagnosed as malignant lesions (Greenspan et al., 1991).

\section{Conclusion}

SPECT/CT combines the sensitivity of bone scintigraphy and specificity of diagnostic $\mathrm{CT}$ and may serve as an important second line imaging modality for the detection of occult carpal fractures.

\footnotetext{
Abbreviations

LT: Lunotriquetral; MR: Magnetic resonance; SL: Scapholunar; SPECT/CT: Single photon emission tomography/ computed tomography; TFCC: Triangular fibrocartilage complex 
Author's contributions

Conception and design: KS, LA, FP, TVW. Acquisition of data, analysis and interpretation of data: KS, WVB, ER, FP, WUK, TK. Drafting the article and final approval of the revised manuscript: KS, LA, WVB, GG, WUK, TVW, ER, FP. All authors read and approved the final manuscript.

Ethics approval and consent to participate

For this case report, informed written consent for publication was obtained from the patient. None ethics approval was needed.

\section{Competing interests}

The authors declare that they have no conflicts of interest or competing interests.

\section{Publisher's Note}

Springer Nature remains neutral with regard to jurisdictional claims in published maps and institutional affiliations.

\section{Author details}

'Department of Radiology and Nuclear Medicine, Lucerne Cantonal Hospital, Lucerne, Switzerland. ${ }^{2}$ Department of Nuclear Medicine, Humanitas Clinical and Research Hospital, Rozzano, Milan, Italy. ${ }^{3}$ Department of Radiology and Nuclear Medicine, Slingeland Hospital, Doetinchem, The Netherlands. ${ }^{4}$ Department of Nuclear Medicine, Royal Free London NHS Foundation Trust, London, UK. ${ }^{5}$ Nuclear Medicine Spitalerhof, Spitalerstraße 8, Hamburg, Germany. ${ }^{6}$ Department of Nuclear Medicine, Antwerp University Hospital, Edegem, Belgium. ${ }^{7}$ Nuclear Medicine, Clinique du Diaconat, Mulhouse, France. ${ }^{8}$ Clinic of Nuclear Medicine, Friedrich-Alexander-University Erlangen-Nürnberg, Erlangen, Germany. ${ }^{9}$ Department of Nuclear Medicine, Hôpital Lariboisière, Paris, France.

Received: 12 July 2018 Accepted: 15 August 2018

Published online: 05 November 2018

\section{References}

Achong DM (2007) Increased uptake in a vertebral bone island seen only on SPECT. Clin Nucl Med 32(8):620-623

Akdemir UO, Atasever T, Sipahioglu S, Turkolmez S, Kazimoglu C, Sener E (2004) Value of bone scintigraphy in patients with carpal trauma. Ann Nucl Med 18(6):495-499

Allainmat L, Aubault M, Noel V, Baulieu F, Laulan J, Eder V (2013) Use of hybrid SPECT/CT for diagnosis of radiographic occult fractures of the wrist. Clin Nucl Med 38(6):e246-e251

Bhure U, Roos JE, Perez Lago MDS, Steurer I, Grunig H, Hug U et al (2017) SPECT/CT arthrography. Br J Radiol:20170635

de Zwart AD, Beeres FJ, Rietbergen DD, Krijnen P, Schipper IB (2015) Initial experience of SPECT/CT in the diagnosis of occult scaphoid fracture. Acta Radiol Open 4(10):2058460115602729

Greenspan A (1995) Bone island (enostosis): current concept--a review. Skelet Radiol 24(2):111-115

Greenspan A, Steiner G, Knutzon R (1991) Bone island (enostosis): clinical significance and radiologic and pathologic correlations. Skelet Radiol 20(2):85-90

Huellner MW, Burkert A, Schleich FS, Schurch M, Hug U, von Wartburg U et al (2012) SPECT/CT versus MRI in patients with nonspecific pain of the hand and wrist - a pilot study. Eur J Nucl Med Mol Imaging 39(5):750-759

Klempka A, Wagner M, Fodor S, Prommersberger KJ, Uder M, Schmitt R (2016) Injuries of the scapholunate and lunotriquetral ligaments as well as the TFCC in intra-articular distal radius fractures. Prevalence assessed with MDCT arthrography. Eur Radiol 26(3):722-732

Lee RK, Ng AW, Tong CS, Griffith JF, Tse WL, Wong C et al (2013) Intrinsic ligament and triangular fibrocartilage complex tears of the wrist: comparison of MDCT arthrography, conventional 3-T MRI, and MR arthrography. Skelet Radiol 42(9):1277-1285

Querellou S, Arnaud L, Williams T, Breton S, Colin D, Le Roux PY et al (2014) Role of SPECT/CT compared with MRI in the diagnosis and management of patients with wrist trauma occult fractures. Clin Nucl Med 39(1):8-13

Shepard NP, Westrick RB, Johnson MR (2014) Fracture of the capitate. J Orthop Sports Phys Ther 44(7):541

Welling RD, Jacobson JA, Jamadar DA, Chong S, Caoili EM, Jebson PJ (2008) MDCT and radiography of wrist fractures: radiographic sensitivity and fracture patterns. AJR Am J Roentgenol 190(1):10-16

\section{Submit your manuscript to a SpringerOpen ${ }^{\circ}$ journal and benefit from:}

- Convenient online submission

- Rigorous peer review

- Open access: articles freely available online

High visibility within the field

- Retaining the copyright to your article

Submit your next manuscript at $\mathbf{s p r i n g e r o p e n . c o m ~}$ 